THREATENED BIODIVERSITY, THE NEMA EIA REGULATIONS AND CULTIVATION OF VIRGIN LAND:

MORE OF THE SORRY SAME?

ISSN 1727-3781

2007 VOLUME 3 


\section{THREATENED BIODIVERSITY, THE NEMA EIA REGULATIONS AND \\ CULTIVATION OF VIRGIN LAND: \\ MORE OF THE SORRY SAME?}

CC de Villiers ${ }^{*}$

\section{Introduction}

Agriculture has had the single greatest impact on habitat loss across South Africa. Its effects on biodiversity patterns and processes have been particularly pronounced in the intensively cultivated and poorly protected lowlands of the Western Cape Province. ${ }^{1}$ In both international and national terms, biodiversity in the Western Cape is disproportionately threatened. Its borders contain significant elements of three out of 34 global biodiversity hotspots ${ }^{2}$ and 66

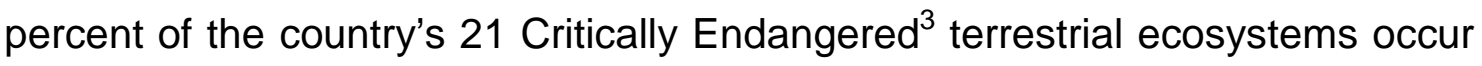
in the Fynbos Biome, which is associated almost exclusively with the Western Cape. ${ }^{4}$ The lowlands renosterveld has borne much of the brunt of three centuries of cereal production: less than nine percent of its original extent still persists. The surviving remnants occur as some 18,000 highly fragmented pockets of vegetation, mostly on privately owned farmland. More than half of these globally threatened patches of lowland renosterveld are less than one

* BA Hons (Stellenbosch), MPhil Environmental Management (Cape Town). Conservation Unit, Botanical Society of South Africa.

1 Cowling et al Framework for a Conservation Plan 17; Scholes and Biggs (eds) "Ecosystem services in South Africa" 18; SANBI NBSAP 12, 14 and 23.

2 The Cape Floristic Region and Succulent Karoo and Sub-tropical Thicket biomes (global biodiversity 'hotspots' refer to regions with above-average species endemism which also are subject to a high degree of threat from human pressures).

3 Cf S 52(2) of the National Environmental Management Biodiversity Act 10 of 2004: critically endangered ecosystems, being ecosystems that have undergone severe degradation of ecological structure, function or composition as a result of human intervention and are subject to an extremely high risk of irreversible transformation; endangered ecosystems, being ecosystems that have undergone degradation of ecological structure, function or composition as a result of human intervention, although they are not critically endangered ecosystems; vulnerable ecosystems, being ecosystems that have a high risk of undergoing significant degradation of ecological structure, function or composition as a result of human intervention, although they are not critically endangered ecosystems or endangered ecosystems; protected ecosystems, being ecosystems that are of high conservation value or high national or provincial importance. Cowling "Foreword" 7; Driver et al 2005 Strelitzia 17; Mittermeier et al Hotspots. 
hectare in extent. ${ }^{5}$ These highly threatened ecosystems have gained their alarming status due to very low levels of statutory protection. ${ }^{6}$

The South African National Biodiversity Institute has identified the Cape Floristic Region and Succulent Karoo as priorities for implementation of the National Biodiversity Strategy and Action Plan. This plan includes strategies for 'mainstreaming' biodiversity into planning and decision-making, sustainable use, conservation and institutional strengthening. ${ }^{7}$ Given the close correlation between cultivation and the risk of irreversible transformation of a globally significant biodiversity, the environmental regulatory regime emerges as a crucial aid to aiding biodiversity conservation in an off-reserve context in the Western Cape. The strength and ambit of legislation and regulatory instruments at the disposal of the state, buttressed by an unprecedented degree of international donor interest and investment in bioregional conservation programmes in South African biodiversity 'hotspots', would seem to confirm this conclusion. ${ }^{8}$ Experience, however, presents a somewhat less encouraging picture.

The challenges associated with a complex legislative environment and with administrative fragmentation are well-recognised. ${ }^{9}$ A key impediment to the coherent, consistent and effective treatment of biodiversity considerations in the agricultural sphere specifically relates to the problem that official decisionmaking about cultivation is legally, administratively and functionally divided between at least three statutory bodies with different objectives. ${ }^{10}$ These

$5 \quad$ Von Hase et al Cape lowlands renosterveld 9 and 22.

$6 \quad$ Ibid at 8; Rouget et al NSBA Technical Report 81-84.

7 SANBI supra $\mathrm{n} 2$ at 17; Driver et al supra $\mathrm{n} 2$ at 18.

8 See, eg, Sandwith et al Mainstreaming Biodiversity 78-90 for an account of donorsponsored biodiversity 'mainstreaming' in three pilot bioregional programmes in South Africa.

9 CSIR Situation Assessment.

10 The CAPE analysis of the legal, institutional and financial context of biodiversity conservation in the Cape Floristic Region among others found that numerous laws and policies indirectly impacted on the protection of biodiversity outside formally protected areas. These were not coordinated into a cohesive framework, they were not implemented consistently, and biodiversity conservation was often incidental to the main aim of the legislation or policy. Furthermore, there was insufficient collaboration between government agencies whose mandate impacted on the conservation of the Cape Floristic Region. 
specifically relate to agricultural, environmental and biodiversity mandates expressed by three distinct pieces of legislation. These acts are: the Conservation of Agricultural Resources Act 43 of 1983; ${ }^{11}$ the Environment Conservation Act 73 of $1989^{12}$ and the National Environmental Management Act 107 of $1998^{13}$ prior to 1 July 2006, thereafter only NEMA; and the Western Cape Nature Conservation Board Act 15 of $1998 .{ }^{14}$ The laws in question are implemented by organs of state representing both the national and provincial spheres of legislative competence.

The revised environmental impact assessment ${ }^{15}$ regime under $\mathrm{NEMA}^{16}$ has addressed convincingly some of the most apparent shortcomings that characterised the issuing of cultivation permits during the ECA dispensation. However, it will be argued that the laudable checks and balances of the NEMA framework of environmental authorisation are currently little more than pyrrhic with respect to agricultural development that entails the transformation of less than three hectares of indigenous vegetation in Critically Endangered and Endangered ecosystems which are not gazetted as such in terms of section 52 of the National Environmental Management: Biodiversity Act 10 of 2004. ${ }^{17}$ Where the latter circumstances prevail, the removal or transformation of threatened indigenous vegetation of itself does not constitute a listed activity requiring environmental authorisation. In fact, there is effectively no difference between the current (that is NEMA) status quo and the situation that prevailed in the Western Cape under the ECA EIA regulations with respect to applications for the cultivation of virgin soil in terms of CARA. The cultivation of

11 Hereafter CARA.

12 Hereafter ECA. The relevant s 21, 22 and 26 of ECA, and notices and regulations pursuant to $s 21$ and 22, were repealed with effect on 1 July 2006 with the publication of revised EIA regulations issued under s 24 of the National Environmental Management Act 107 of 1998.

13 Hereafter NEMA.

14 Hereafter WCNCBA.

15 Hereafter EIA.

16 Chiefly through the identification of "(the) transformation or removal of indigenous vegetation of 3 ha or more or of any size where the transformation or removal would occur within a critically endangered or endangered ecosystem listed in terms of $s 52$ of the National Environmental Management: Biodiversity Act, 2004 (Act 10 of 2004)" as an activity requiring environmental authorisation in terms of s 24 and 24D of NEMA (Item 12 of GN R386 of 21 Apr 2006).

17 Hereafter NEMBA. 
virgin soil ${ }^{18}$ was not considered a listed activity ${ }^{19}$. The Western Cape Department of Environmental Affairs and Development Planning ${ }^{20}$ was reduced to a commenting body. Notwithstanding a Memorandum of Agreement on the Cultivation of New Agricultural Fields ${ }^{21}$ that was meant to co-ordinate and reconcile the diverse regulatory functions under the 'ECA dispensation', the contracting parties ${ }^{22}$ failed to find an effective legal mechanism for ensuring that environmental and biodiversity-related comments could be integrated as enforceable conditions into cultivation permits.

This article therefore sets out to identify, on the basis of an analysis of the circumstances that gave rise to the Agreement, some of the key issues that inhibited 'mainstreaming' of biodiversity in agri-environmental ${ }^{23}$ decisionmaking in the Western Cape in the period preceding the promulgation of the NEMA EIA regulations. It also attempts to show that the NEMA EIA dispensation has inherited most of these problems in respect of cultivation that would result in the transformation or removal of less than three hectares of vegetation in Critically Endangered and Endangered ecosystems-which, until listed in terms of section 52 of NEMBA, will have no protection in law. Lastly, the article will analyse and suggest a number of options for ensuring that biodiversity is given its appropriate due in the issuing of cultivation permits that otherwise may contribute to the further degradation and loss of some of the most threatened elements of the globally unique Cape flora.

18 Reg 2(1), GN R1048 of 25 May 1984.

19 Item 10, sch 1 of GN R1182 of 5 Sep 1997 as amended.

20 Hereafter DEADP.

21 Hereafter the Agreement.

22 DEADP, the NDA, the Western Cape Department of Agriculture, the Department of Water Affairs and Forestry, and CapeNature.

23 'Agri-environmental' decision-making refers to situations in which both agricultural and environmental authorisations must be obtained in order to undertake an agriculture-related activity such as the cultivation of virgin soil. 


\section{Legal and administrative context}

The central theme of this paper is that environmental decision-making about the biodiversity aspects of the cultivation of new lands continues, notwithstanding important reforms introduced by the NEMA EIA regulations, to be hamstrung by problems peculiar to the interpretation and implementation of the former ECA EIA regulations in the Western Cape. This and the following sections set out to substantiate this assertion by analysing agri-environmental decision-making in two distinct phases demarcated by the advent of the NEMA EIA regulations in July 2006. The first period has its inception in May 2002 when the cultivation of virgin ground ${ }^{24}$ was added to the list of prescribed activities requiring environmental authorisation under the ECA. ${ }^{25}$ The second period was initiated some four years later by the repeal of the ECA EIA regulations and their replacement by regulations under NEMA. Procedures relating to the enforcement of CARA and its regulations have remained unaltered in this time, as have constitutional and legal precepts under-pinning co-operative governance. A unifying theme throughout this analysis is that whereas the promulgation of the NEMA EIA regulations represented a watershed in terms of placing agricultural planning and development under an unprecedented degree of formal environmental oversight, key failings of the previous, ECA-defined system have been transferred, unamelioriated, into the new one.

\subsection{The constitutional dimension}

The Constitution ${ }^{26}$ provides for an environmental right and defines the framework whereby responsibility for the various facets of agri-environmental decision-making is assigned to different spheres of government. Section 24 of the Bill of Rights states that everyone has the right to have the environment protected through reasonable laws or other means that prevent pollution and ecological degradation, promote conservation and secure ecologically

24 Item 10, GN R670 and GN R672 of 10 May 2002.

25 Ss 21, 22 and 26.

26 Constitution of the Republic of South Africa, 1996. Hereafter the Constitution. 
sustainable development and use of natural resources while promoting justifiable economic and social development. This right, in balance with others, ${ }^{27}$ binds, inter alia, all organs of state. ${ }^{28}$

The legal and administrative environment within which agricultural decisionmaking takes place spans two spheres of government, national and provincial. This involves at least three functional areas of concurrent national and provincial legislative competence, that is, agriculture, environment and nature conservation (excluding national parks, national botanical gardens and marine resources). ${ }^{29}$ In terms of national legislation, the national Department of Agriculture, through the Directorate: Agricultural Land and Resources Management, is exclusively responsible for the implementation and enforcement of the Conservation of Agricultural Resources Act 43 of 1983 and its regulations. The Western Cape DEADP has, in turn, delegated authority ${ }^{30}$ as the competent authority responsible for administering and enforcing NEMA and, previously, the ECA, and their respective EIA regulations. This function is assigned to the Directorate: Environmental and Land Management.

There is one directly applicable piece of provincial legislation, namely the Western Cape Nature Conservation Board Act 15 of 1998, which, inter alia, confirms CapeNature's role as the statutory custodian of biological diversity in the Western Cape. However, regulatory powers have not been conferred on CapeNature in terms of section 9(1) of the act.

\subsection{The cultivation of virgin soil, 10 May 2002-3 July 2006}

New EIA regulations under NEMA came into force on 3 July $2006 .{ }^{31}$ Prior to this, regulatory control over the cultivation of new lands was dominated almost exclusively by CARA unless applicants intended undertaking an activity listed under section 21 of the ECA. The broad objective of CARA is the conservation 
of agricultural resources which includes maintaining the production potential of land, combating erosion, protecting vegetation and combating weeds and invader plants.

The act provides for prescribed Control Measures, ${ }^{32}$ enforced through regulations. ${ }^{33}$ A directive also may be issued in order to compel landowners to comply with a Control Measure. ${ }^{34}$ Control Measures, inter alia, apply to the cultivation of 'virgin soil', where 'virgin soil' means:

...land which in the opinion of the executive officer has at no time during the preceding ten years been cultivated. ${ }^{35}$

The regulations also deal with other aspects of agricultural resource conservation, including cultivation of land with a slope, protection of cultivated land against erosion through the action of water and wind, and utilisation and protection of vleis, marshes, water sponges and water courses. Permits for the cultivation of virgin soil are issued in terms of regulation 2, R1048 of 25 May 1984. In terms of regulation 2(1), an applicant may be directed to dig soil pits and undertake other, unspecified, "steps (for) the purpose of an investigation deemed necessary to consider an application (for a cultivation permit)". Permit conditions typically could provide for interventions such as soil conservation works to divert run-off, the establishment of fields perpendicular to the dominant wind direction, and the planting of cover crops. In the Western Cape, agricultural extension services are provided by the LandCare programme in the Western Cape Department of Agriculture. The latter department does not have executive powers under CARA and it only fulfils an advisory function in agricultural decision-making.

The formal, environmental aspects of agricultural planning and development were dominated by ECA from 1989 to mid-2006. ${ }^{36}$ However, cultivation of virgin 
soil did not require environmental authorisation prior to May 2002, when the then-EIA regulations underwent a number of amendments. ${ }^{37}$ There may, however, have been exceptional cases prior to May 2002 where farmers were required to obtain ECA authorisation for intending to undertake -

(the) change of land use from ... use for grazing to any other form of agricultural use. ${ }^{38}$

Of direct relevance to the administration of agricultural permit applications was the introduction in May 2002 of an additional listed activity to Schedule 1 of GN R1182, namely Item 10, "(the) cultivation or any other use of virgin ground". 39

In the Western Cape, the former Department of Environmental and Cultural Affairs and Sport (hereafter DECAS) obtained a legal opinion ${ }^{40}$ on the ECA EIA amendments of May 10, 2002. This opinion held that the DECAS could not apply Item 10 of Schedule 1 of GN R1182 until a commencement date had been set and reached. ${ }^{41}$ DECAS subsequently issued a circular in which recipients were, inter alia, reminded of the general duty of care prescribed in

36 The objective of ECA was to provide for the effective protection and controlled utilisation of the environment. The act provided for the identification of activities which would probably have a detrimental effect on the environment. It also stipulated procedures for investigating and reporting on potential environmental impacts of the proposed project and alternatives. Sch 1 of GN R1182 of 5 Sep 1997 as amended identified activities that required authorisation in terms of $\mathrm{s} 22$ of the ECA. Minimum prescribed procedures for obtaining authorisation under s 21 and 22 of the ECA were captured in GN R1183 of Sep 1997 as amended.

37 GN R670 and GN R672 of 10 May 2002.

38 Item 2(c), GN R1182 of 5 Sep 1997.

39 'Virgin ground' is defined as "land which has at no time during the preceding 10 years been cultivated". This definition is virtually identical to that of 'virgin soil' in CARA.

40 Ref E12/2/R 30 Jul 2002, Chief Director: Environmental Affairs, Department of Environmental and Cultural Affairs and Sport.

41 The relevant excerpt from the legal opinion reads: "(No) date has been fixed in Schedule 2 for the commencement of the new item 10 in schedule 1, namely the 'cultivation or any other use of virgin ground'. It follows from the second paragraph of the Identification (of activities which may have a substantial detrimental effect on the environment by the Minister of Environmental Affairs and Tourism under s 21 the Environment Conservation Act, 73 of 1989) that item 10 in schedule 1 is not yet in force. The relevant part of that paragraph reads as follows: '... this notice will commence in respect of different activities on the dates indicated in Schedule 2...' Consultant may not apply item 10 of schedule 1 until a commencement date has been set and that date has been reached." (Ref E12/2/2R 30 Jul 2002, supra n 40). 
section 28 of NEMA. ${ }^{42}$ The opinion did not, however, offer any technical guidance as to how the 'duty of care' was to be applied to applications for cultivation permits under CARA which did not constitute listed activities in terms of ECA. On the basis of this opinion, DECAS and its successor, the DEADP, elected not to enforce the 'virgin ground' provision of the May 2002 amendments to the former EIA regulations. 43 In practice, this meant that the Western Cape environmental authority effectively reduced itself to a commenting body when forfeiting its powers to exercise any direct form of environmental control over the issuing of permits for the cultivation for virgin land in terms of CARA. The department did, however, retain regulatory control over agricultural projects that triggered other activities listed in terms of section 21 of ECA (such as the construction of roads or dams or the change of land use from grazing to any other agricultural use). ${ }^{44}$

\subsection{NEMA and the cultivation of virgin soil}

The other piece of legislation that dominated the agri-environmental administrative landscape in the 'ECA period' is NEMA, national framework legislation which has co-operative governance as one of its primary objectives. Among others, the act recognises that the environment is a functional area of concurrent national and provincial legislative competence. It states that all spheres of government and all organs of state must co-operate with, consult and support one another. ${ }^{45}$ The act creates the foundation for co-operative environmental governance by establishing principles (the National Environmental Management Principles) for decision-making on matters

42 S 28 states that every person who causes, has caused or may cause significant pollution or degradation of the environment must take reasonable measures to prevent such pollution or degradation from occurring, continuing or recurring, or, in so far as such harm to the Environment is authorised by law or cannot reasonably be avoided or stopped, to minimise and rectify such pollution or degradation of the environment.

43 The non-enforcement of the 'virgin ground' listed activity in the Western Cape is believed to have been exceptional in national terms. For a different provincial (KwaZulu-Natal) perspective, see Cox and Youens 2005 Review.

44 Items 1(d) and (j), and Item 2(d) of GN R1182 of 5 Sep 1997 as amended.

45 'Preamble' of NEMA. At least in terms of its stated intention, NEMA would appear to be of immense relevance to the issuing of permits and authorisations pertaining to cultivation of virgin land in priority conservation areas in the Western Cape. 
affecting the environment. ${ }^{46}$ Furthermore, the National Environmental Management Principles serve as guidelines by reference to which any organ of state must exercise any function when taking any decision in terms of any statutory provision concerning the protection of the environment. ${ }^{47}$

The National Environmental Management Principles appear to present firm guarantees that biodiversity will be given appropriate consideration in the course of agri-environmental decision-making. For example, factors that must be considered for the purposes of sustainable development, inter alia, include "(avoiding), minimising and remedying the disturbance of ecosystems and loss of biodiversity", 48 "(avoiding) jeopardising ecosystem integrity", ${ }^{49}$ and "(paying) specific attention to management and planning procedures pertaining to sensitive, vulnerable, highly dynamic or stressed ecosystems". ${ }^{0}$ The requirement for co-ordinated decision-making likewise is exemplified through principles that oblige the pursuit of the "best practicable environmental option" by means of integrated environmental management, ${ }^{51}$ and ensuring "intergovernmental co-ordination and harmonisation of policies, legislation and actions relating to the environment". ${ }^{52}$ The principles also guide the interpretation, administration and implementation of NEMA, and any other law concerned with the "protection or management of the environment". 53 CARA would appear to correspond to the latter definition to the extent that its objectives embrace the conservation of clearly defined components of the biophysical environment (for example, soil, ${ }^{54}$ wetlands $^{55}$ and vegetation including 'veld' ${ }^{\text {56 }}$ ). From the foregoing, it appears that CARA would have to be

$46 \mathrm{~S} 2$ of NEMA.

47 S 2(1)(c) of NEMA.

48 S 2(4)(a)(i) of NEMA.

$49 \mathrm{~S} 2(4)(\mathrm{a})(\mathrm{vi})$ of NEMA.

50 S 2(4)(r) of NEMA.

51 S 2(4)(b) of NEMA.

52 S 2(4)(I) of NEMA.

$53 \mathrm{~S} 2(1)(\mathrm{e})$ of NEMA.

54 Cf objectives and S 6(2)(a) of CARA.

55 Cf objectives and S 6(2)(e) of CARA.

56 Cf objectives and S 6(2)(g) of CARA; also definition of 'grazing capacity' (s 1) which "(in) relation to veld, means the production capacity over the long term of that veld to meet the feed requirements of animals in such a manner that the natural vegetation (own emphasis) thereon does not deteriorate or is not destroyed". 
interpreted and enforced in terms of the National Environmental Management Principles in so far as it (CARA) constitutes a "law concerned with the protection or management of the environment". ${ }^{57}$

Chapter 3 of NEMA provides for co-operative governance by means of two mechanisms, Environmental Implementation Plans and Environmental Management Plans. ${ }^{58}$ Of relevance here is the provision that the Department of Agriculture is listed as a national department exercising functions "which may affect the environment" (NEMA, Schedule I) and must therefore prepare an Environmental Implementation Plan (hereafter EIP). Such an EIP must describe, among others: policies, plans and programmes that may significantly affect the environment; and how the department ensures that its functions are exercised in terms of the national environmental management principles and other relevant legislative provisions. It follows that the national Department of Agriculture must be able to show the Director-General of the Department of Environmental Affairs and Tourism how it ensures that its regulatory functions in terms of CARA comply with the National Environmental Management Principles. ${ }^{59}$

Having been granted a permit under CARA to cultivate virgin soil, the farmer still would have to comply with the duty of care provisions set out in section 28 of NEMA if his (sic) activities could be deemed to degrade the environment significantly. Furthermore, section 28(3) of NEMA sets out prescribed measures for preventing and remedying such degradation, which could include investigating, assessing and evaluating the impact on the environment. Such measures can be ordered by means of a directive issued in terms of section $28(4)$ of the act. Of note is that section $28(1)$ explicitly recognises that legally sanctioned activities may result in environmental degradation which requires

57 S 2(1)(e) of NEMA.

$58 \mathrm{~S} 11(1)$ and 11(2) of NEMA.

59 Furthermore, non-consideration of the National Environmental Management Principles in the course of decision-making potentially could expose an administrative action to judicial review in terms of s 6 of the Promotion of Administrative Justice Act 3 of 2000 (PAJA). 
reasonable mitigatory measures to give effect to the duty of care. ${ }^{60}$ The duty of care therefore also refers to anticipated impacts that may arise as result of an activity that in all other respects would be considered lawful-such as, for example, the cultivation of virgin land for which permission has been obtained in terms of CARA. Read in conjunction with section 28(3) of NEMA which, inter alia, provides for prior impact assessment ${ }^{61}$ and modification of an act, ${ }^{62}$ the duty of care provisions would appear to offer organs of state considerable flexibility in prescribing reasonable, pre-emptive (own emphasis) and enforceable environmental restrictions that are tailored to the specific circumstances of approved activities, such as the cultivation of virgin soil. The Director-General, Environmental Affairs and Tourism, or the provincial head of the responsible department, is empowered to issue and enforce directives under section 28(4). This means that the DEADP has the authority to enforce the Duty of Care provisions of NEMA. Directives would be the vehicle by means of which the principles and practices of integrated environmental management could be preemptively inserted into the regulatory domain of other departments whose decisions would result in approvals that may cause significant degradation of the environment. A directive issued in terms of section 28(4) would have to be preceded by consultation with any other organ of state concerned. Affected persons also would have to be afforded an adequate opportunity to inform the provincial head of department of their relevant interests. ${ }^{63}$ When considering any measure or time period envisaged in section 28(4), the relevant head of department would, among others, have to regard the National Environmental Management Principles, the severity of any impact on the environment, any measures proposed by the person on whom measures are to be imposed under section $28(4)$ and the desirability of the State fulfilling its role as custodian holding the environment in public trust. ${ }^{64}$

60 Cf S 28(1) of NEMA: "Every person who causes, has caused or may cause significant pollution or degradation of the environment must take reasonable measures to prevent such pollution or degradation from occurring, continuing or recurring, or, in so far as such harm to the environment is authorised by law or cannot reasonably be avoided or stopped, to minimise and rectify such pollution or degradation of the environment." (Own emphasis).

61 S 28(3)(a) of NEMA.

62 S 28(3)(c) of NEMA.

$63 \mathrm{~S} 28(4)$.

64 S 28(5)(a), (c), (d) and (e). 
In terms of the administration of CARA approvals between 10 May 2002 and 3 July 2006 (that is, when the cultivation of virgin ground was not enforced as a listed activity under ECA in the Western Cape), it is inferred from the foregoing that section 28 of NEMA offered DEADP an opportunity to hold real, enforceable sway over the consideration of environmental impacts relating to approvals for the cultivation of virgin soil under CARA-and irrespective of whether or not the latter also required environmental authorisation in terms of section 22 of ECA.

Prior to the promulgation of the National Environmental Management Second Amendment Act 8 of 2004 (hereafter the NEM Second Amendment Act), section 24(1) of NEMA provided that the potential impacts of activities that required permission by law (including, for example, cultivation permits under CARA), and which could significantly affect the environment, had to be considered, investigated and assessed prior to their implementation. ${ }^{65}$ Such assessment had to be reported to the organ of state responsible for authorising or permitting an activity. This provision commonly became known as the 'twotier test' for determining if an official decision had to be preceded by an environmental assessment. The original section 24(1) of NEMA provided a useful legal instrument to hold government departments accountable for the potential environmental consequences of their decisions. It was, however, repealed with the promulgation of the NEM Second Amendment Act which introduced a significant restriction in the scope of environmental oversight over official decision-making. The implications of the latter act for agricultural decision-making are discussed below.

\subsection{The NEM Second Amendment Act and cultivation}

As noted above, the NEM Second Amendment Act did away with the so-called two-tier test that was provided for by NEMA section 24(1). In addition, the act qualified the scope of minimum procedures for the investigation, assessment 
and communication of the potential environmental impacts of activities by limiting such procedures to "every application for an environmental authorisation". ${ }^{66}$ Previously, NEMA section 24(1) referred to the consideration, investigation, assessment and reporting of potential impacts of broadly-defined 'activities' whose definition extended to "policies, programmes, plans and projects", ${ }^{67}$ that is, a considerably more inclusive definition than that provided by the amended sections 24(1) and 24(4) of the NEM Second Amendment Act.

In the case of applications for cultivation permits under the CARA which did not require authorisations in terms of ECA before 3 July 2006, it would appear doubtful as to whether the "general objectives of integrated environmental management" as circumscribed the NEM Second Amendment Act would have applied to decision-making that amounted to an exclusive administrative prerogative of the NDA. If this understanding holds true, it would mean that under the 'post-May 2002 ECA dispensation', and following the promulgation of the NEM Second Amendment Act, there was no legal requirement on the applicant for a cultivation permit to investigate and report on the potential impacts of that activity, seek the best practicable option through the selection of feasible alternatives, or to undertake a public participation process as required by section 24(4) of the NEM Second Amendment Act.

This situation was, of course, dramatically altered once the NEMA EIA regulations came into force on 3 July 2006. The implications of these regulations for the control of the environmental aspects of the cultivation of virgin soil are considered more fully in the next section. But as argued throughout this paper, the protection that the NEMA EIA regulations could have extended to our most threatened terrestrial biodiversity is annulled by an arbitrary, three hectares, transformation threshold and the absence of a national list of threatened ecosystems. Without the latter in place, the statutory protection offered a significant proportion of threatened terrestrial biodiversity in 
agricultural landscapes in South Africa is markedly threadbare-and certainly is no better than that which prevailed prior to July 2006.

\subsection{The NEMA EIA regulations}

Environmental impact assessment regulations published in terms of NEMA came into effect on July $3,2006 .{ }^{68}$ Of direct relevance to the regulation and control of the clearance of land for the purposes of cultivation are Items 12 of GN R386, and Item 2 of GN R387. In the case of Item 12, environmental authorisation $^{69}$ is required for:

The transformation or removal of indigenous vegetation of 3 ha or more or of any size where the transformation or removal would occur within a critically endangered or endangered ecosystem listed in terms of section 52 of the National Environmental Management: Biodiversity Act, 2004 (Act 10 of 2004).

A Basic Assessment ${ }^{70}$ must be applied to an application for this activity.

The scoping and EIA route ${ }^{71}$ must be pursued where cultivation constitutes an activity consistent with Item 2 of GN R387, that is:

Any development activity, including associated structures and infrastructure, where the total area of the developed area is, or is intended to be, 20 hectares or more.

The Basic Assessment and scoping and EIA procedures require compliance with the general objectives of Integrated Environment Management ${ }^{72}$ provided for in Chapter 5 of NEMA. The latter includes the mandatory consideration of alternatives, public participation, and impact assessment, evaluation and mitigation. None of these definitive features of integrated environmental

68 GN R385, GN R386 and GN R387 of 21 Apr 2006, published in terms of s 24(5), read with $S 44$ of NEMA.

69 S 24(1) of NEM Second Amendment Act.

70 Reg 22, GN R385 of 21 Apr 2006.

71 Reg $27 \mathrm{ff}, \mathrm{GN}$ R385 of 21 Apr 2006.

72 S 23(2) of NEMA. 
management ${ }^{73}$ applied to applications for the cultivation of virgin soil when these were regulated by CARA exclusively.

\subsection{The National Environmental Management: Biodiversity Act 10 of 2004}

The National Environmental Management: Biodiversity Act 10 of $2004^{74}$ currently has negligible influence over environmental assessment and management. Nonetheless it has potentially major significance in terms of introducing mandatory biodiversity considerations-at scale-to planning and authorisation processes relating to land use. Besides giving effect to the Convention on Biological Diversity and other ratified international agreements relating to biodiversity, NEMBA closely dovetails with the IEM aspects of NEMA by providing for the regulation of restricted activities in areas defined by threats to ecosystems or species. ${ }^{75}$ In summary, the NEMBA provides for a form of 'tailor-made' environmental impact assessment dispensation in certain areas, or involving specifically listed activities, that is, informed by the prerogatives of the conservation and sustainable use of biodiversity. These provisions, which are contained in sections $52^{76}$ and $53,{ }^{77}$ are directly linked to the integrated environmental management provisions of the NEM Second Amendment Act.

Reference needs to be made to chapter 5 of NEMA in order to illustrate the implications of the NEMBA for the regulation of agricultural land-use change. The most directly-applicable provisions of chapter 5 of NEMA are those that relate to the identification of activities (own emphasis) which may not be commenced without environmental authorisation, ${ }^{78}$ and the identification of geographical areas (own emphasis) in which specified activities may not be

73 Cf DEA Guideline Document; Glasson et al Introduction 4-6 ff; Preston et al IEM 748-761;

74 Hereafter NEMBA.

75 De Villiers et al "Developing Guidelines".

77 S 52(1)(a), The Minister may, by notice in the Gazette, publish a national list of ecosystems that are threatened and in need of protection.

76 S 52(1)(a), The Minister may, by notice in the Gazette, publish a national list of ecosystems that are threatened and in need of protection.

77 S 53 (1), The Minister may, by notice in the Gazette, identify any process or activity in a listed ecosystem as a threatening process.

78 S 24(2)(a) of NEM Second Amendment Act. 
commenced without prior authorisation. ${ }^{79}$ In the latter instance, the trigger for environmental investigation is a spatially-explicit environmental attribute rather than an activity in its own right. ${ }^{80}$ The act also provides that information and maps can be compiled which detail the attributes of the environment in particular geographical areas. ${ }^{81}$ The sensitivity of such attributes must be taken into account by every competent authority. ${ }^{82}$

The NEMA section 24 provisions relating to the control of specified activities in identified areas closely correspond with the NEMBA's approach to the control of 'threatening processes' in listed ecosystems. ${ }^{83}$ The NEMBA does not define 'threatening processes' as these must be identified by means of a notice published in the Government Gazette. The NEMA EIA regulations have, in a sense, 'run ahead' in this regard by effectively identifying in Item 12 of Schedule $1^{84}$ two types of 'threatening process', that is, the transformation or removal of indigenous vegetation (without specifying the actual means or object of such removal). What is absent from this equation, of course, is the listing of Critically Endangered and Endangered ecosystems in terms of the NEMBA. For 'threatening processes' to be regulated under the NEMBA, the Minister would have to gazette a list of threatened ecosystems under section 52 of the $\mathrm{Act}^{85}$ (in which case 'threatened ecosystems' would be synonymous with the 'geographic areas' of section 24, NEMA). The Minister also would have to gazette a list of threatening processes or activities in terms of section 53(1) of the NEMBA which would be synonymous with the 'specified' activities referred to in section 24(2)(b) of the NEMA. Section 24(2)(b) of NEMA requires that

79 S 24(2)(b) of NEM Second Amendment Act.

80 In the Western Cape, the DEADP's Chief Directorate: Environmental and Land Management of the Department of Environmental has initiated a project to supplement the NEMA EIA regulations. This project inter alia entails identification of sensitive and nonsensitive areas (based on environmental attributes) and the identification of activities requiring authorisation from the department (DEADP Presentation).

81 S 24(2)(3) of NEM Second Amendment Act.

82 S 24(3) of NEM Second Amendment Act.

83 S 53 of NEMBA.

84 GN R386 of 21 Apr 2006.

85 le, effectively geographic areas identified in terms of $s$ 24(2)(b) of NEM Second Amendment Act. 
specified activities contemplated in such geographic areas must be authorised by the Minister or the MEC.

It is probable that such threatened ecosystems would be derived from an updated version of the National Spatial Biodiversity Assessment, ${ }^{86}$ which provides a threat status for ecosystems and vegetation types identified in terms of the new classification of South African vegetation. ${ }^{87}$ The NSBA rates the threat status of ecosystems in terms of categories defined by the NEMBA, namely as Protected, Vulnerable, Endangered or Critically Endangered. ${ }^{88}$

Until the requisite notices have been published in the Government Gazette, the provisions of the NEMBA that relate to threatening processes in listed ecosystems have no practical implications for environmental assessment procedures. Moreover, the general objectives of integrated environmental management ${ }^{89}$ would not apply to applications for the cultivation of virgin soil that would result in the transformation or removal of less than three hectares of vegetation in a threatened ecosystem which is not listed in terms of section 52 of NEMBA.

\subsection{The Western Cape Nature Conservation Board Act 15 of 1998 (WCNCBA)}

The Western Cape Nature Conservation Board Act 15 of 1998 states that objectives of the Board shall be to, inter alia, promote nature conservation in the province. 'Nature conservation' is defined as:

...the conservation of naturally-occurring ecological systems and the sustainable utilisation of indigenous plants and animals and the promotion and maintenance of biological diversity within those systems, with due regard to the need to preserve objects of

86 Driver et al supra $\mathrm{n} 2$ at 17.

87 Mucina and Rutherford 2006 Strelitizia 19.

88 S 52(2) of NEMBA.

89 S 24 of NEM Second Amendment Act. 
geological, archaeological, historical, ethnological, educational, oceanographic or scientific interest... ${ }^{90}$

CapeNature engages with agricultural decision-making at various levels, include site visits and formulating specialist ecological input that is conveyed to the Department of Environmental Affairs and Development Planning and the national Department of Agriculture. However, the Western Cape Nature Conservation Board Act does not confer any power on CapeNature (formerly Cape Nature Conservation) to enforce its comments in the domain of agricultural permit procedures. Neither is it a 'competent authority' as defined and provided for in the ECA ${ }^{91}$ and, subsequently, NEMA, ${ }^{92}$ or an "executive officer and authorised person"93 designated to exercise powers and duties under the Conservation of Agricultural Resources Act. The organisation therefore fulfils a strictly advisory or commenting function in relation to procedures for the issuing of cultivation permits under the CARA.

\section{Memorandum of Agreement on the cultivation of new agricultural fields}

The alignment of different departmental mandates and regulatory functions around the goal of sustainable agricultural development has been a focal question that has preoccupied the Western Cape environmental authorities and their agricultural counterparts for nearly a decade. Deliberations in this regard have focused on a Memorandum of Agreement (hereafter the Agreement) which was initiated in response to the new ECA EIA regulations by the then Cape Nature Conservation's Development Evaluation Unit (the precursor the EIA function under DECAS) and the NDA in June $1998 .{ }^{94}$ The core objective of the Agreement was to allow applicants to follow a single process when applying

90 S 1 of WCNCBA.

$91 \mathrm{~S} 1$ of ECA.

92 S1(c) of NEM Second Amendment Act.

$93 \mathrm{~S} 4$ of CARA.

94 Gerber, DEADP, quoted in CAPE Agri-forum Minutes, ie, the "Introductory Discussion on Memorandum of Understanding for the Cultivation of New Agricultural Lands", convened by CAPE. 
for the authorisations and approvals required in terms of the ECA and CARA respectively. ${ }^{95}$ This section introduces the parties to the Agreement, summarises its objectives and critically analyses the procedures by which the parties have attempted to ensure that environmental and biodiversity considerations were factored into CARA permits where there was no ancillary requirement for environmental authorisation under NEMA.

The parties to the Agreement are the DEADP, the national Department of Agriculture (hereafter the NDA), the provincial Department of Agriculture (hereafter the PDA), the Department of Water Affairs and Forestry, and CapeNature. The Agreement has undergone several amendments. ${ }^{96}$ The title of the October 2005 draft reads "Agreement of co-operation concerning the streamlining of the application and review processes for the cultivation of new agricultural fields". The Agreement specifically only pertains to the cultivation of new agricultural fields. According to the preamble, the Agreement recognises that although the various authorities involved in environmental management in the agricultural sector administer different regulatory systems, ${ }^{97}$ they share the goal of 'sustainable agricultural development'.

\subsection{Cultivation permits: Need for co-ordination}

The Agreement recognises that there is a constitutional imperative to coordinate and streamline the requirements of the various authorities thus involved. ${ }^{98}$ Therefore, within the framework of co-operative governance and co-

95 De Villiers and Turner "Managing agricultural land transformation".

96 At the time of writing, the Agreement was in the process of being redrafted as a 'Regulation 6 Agreement' in terms of GN R385 of 21 Apr 2006. It is not known if this would have any relevance for the regulatory implications of transforming or removing less than 3 ha of threatened indigenous vegetation.

97 le, in terms of CARA, EIA regulations as promulgated under the ECA, and the National Water Act 36 of 1998. Applicable framework legislation is listed as: the Constitution, NEMA and PAJA.

98 Cf s 41(1) of the Constitution: "All spheres of government and all organs of state within each sphere must.... (e) respect the constitutional status, institutions, powers and functions of government in the other spheres; (f) not assume any power or function except those conferred on them in terms of the Constitution; $(\mathrm{g})$ exercise their powers and perform their functions in a manner that does not encroach on the geographical, functional or institutional integrity of government in another sphere; and (h) co-operate with one another in mutual trust and good faith by- (i) fostering friendly relations; (ii) assisting and supporting 
ordinated decision-making, the stated aim of the Agreement is to ensure that the regulatory objectives of all authorities are being satisfactorily served, decision-making is well informed and integrated, administrative action is lawful, reasonable and procedurally fair, actual and potential conflicts are resolved. Broadly speaking, the Agreement serves as a set of guidelines that deal with matters such as the submission and routing of application forms, site visits, time limits and the roles of the respective authorising or commenting bodies. It also includes procedures for avoiding and resolving conflicts that are premised on consensus-seeking and also provide for mediation and arbitration. ${ }^{99}$

Under scrutiny here are the two chief avenues of authorisation that characterised agri-environmental decision-making prior to the NEMA EIA regulations. The first related to the co-ordination of the respective regulatory mandates where an application for a ploughing permit under CARA section 6 also constituted an activity listed under section 21 of ECA, triggering the need for an environmental authorisation. The second scenario that fell within the ambit of the Agreement entailed those circumstances where only a CARA permission was necessary, that is, the applicant did not have to obtain authorisation in terms of section 22 of ECA. In the former instance, agricultural decision-making was complemented by formal consideration of the environmental aspects of cultivation by means of the prescribed EIA mechanism; the implication being that if an application did not pass environmental muster, the anticipated cultivation of virgin soil would be prohibited. This was not the case where only CARA prevailed. It is the latter instances that are of direct, effectively unchanged, consequence for the current state of affairs with respect to the proposed transformation or removal of less than three hectares of Critically Endangered or Endangered vegetation for the purposes of cultivation.

one another; (iii) informing one another of, and consulting one another on, matters of common interest; (iv) co-ordinating their actions and legislation with one another; (v) adhering to agreed procedures; and (vi) avoiding legal proceedings against one another."

99 Disputes that cannot, in theory, be resolved within the framework of the Agreement must be referred to the Western Cape Minister of Environment, Planning and Economic Development who must determine whether to refer it to conciliation under s 17(1)(i) of NEMA, or to arbitration under s 19 of the act. 
According to the Agreement, the NDA had to withhold issuing a cultivation permit until the DEADP had commented on the CARA application. ${ }^{100}$ The DEADP's comment would be made "in terms of NEMA". The Agreement provided that CapeNature would comment directly to the DEADP. ${ }^{101}$ If the DEADP commented that additional information (such as a botanical survey) was required to make an informed decision, the national Department of Agriculture would not make a decision without the outstanding information. The CARA applicant would be informed accordingly.

The Agreement did not indicate if the NDA was obliged to consider DEADP's comment (or the recommendations of a specialist report). Neither did it stipulate to what extent the NDA could exercise discretion in terms of accepting, modifying or rectifying such comment. In effect, the Agreement stopped short of presenting a mechanism by which the DEADP's comments on the environmental aspects of cultivation applications could be enforced. The overriding implication is that the NDA was not compelled to give effect to the DEADP comment when issuing cultivation permits. Furthermore, the Agreement gave no hint as to the ramifications, if any, that could follow were environmental comment to be ignored in the agricultural authorisation process.

\subsection{Environmental and biodiversity comments: an untidy juggling act}

This lack of clarity is not only an abstract one. As noted by the Minutes of the first meeting of the CAPE 'Agri-forum' on 24 August 2005, the concern was articulated that:

...(commenting) authorities (within the Provincial Government of the Western Cape) feel their inputs are not always adequately integrated into permits and other authorisations which are subject to national legislation. ${ }^{102}$

100 Par 2.12, of the Agreement.

101 A separate Memorandum of Understanding (MoU) established a general framework for interaction between the DEADP and the Western Cape Nature Conservation Board.

102 "A big concern is that if an application (for the cultivation of virgin soil) would impact on a critical ecological corridor, such as for leopard movement in the Greater Cederberg Biodiversity Corridor, (CapeNature) would not support it - but (CapeNature's) comments 
This opinion appears to be substantiated by data prepared for CapeNature's annual biodiversity review in 2005. According to "cultivation statistics" ${ }^{103}$ tabled by the organisation's Land-use Advisory Unit, it was invited to comment on 121 applications for the cultivation of virgin soil in the 21 months from January 2004 to September 2005. Of these applications, 66 were approved-15 percent of which were "in conflict" with CapeNature's recommendations (which, in terms of its powers, deals virtually exclusively with biodiversity considerations). Some three percent of the permit applications were turned down by the NDA. The grounds given for refusal apparently included "steep slopes, inappropriate crops for the area and wetlands (being present)". ${ }^{104}$ These decisions, as reported by CapeNature, all hinged on matters subject to prescribed control measures identified under section 6 of the Conservation of Agricultural Resources Act and further elaborated by regulations. ${ }^{105}$

\subsection{The national Department of Agriculture, NEMA and cultivation permit}

There appears to be acceptance among the parties to the Agreement that seemingly divergent statutory mandates at least partly explain expressions of unhappiness about deficiencies in the treatment of environmental aspects of cultivation proposals in agricultural decision-making.

As noted by an official in the national Department of Agriculture's Directorate: Agricultural Land and Resources Management:

(our) law is the Conservation of Agricultural Resources Act (and) we must apply the act in terms of its objectives, that is, developing the productive potential of agricultural resources.... 106

carry no weight with the national Department of Agriculture." Bowie (CapeNature) in the CAPE Agri-forum Minutes.

103 Bowie "Land-use Advice".

104 Ibid.

105 GN R1048 of 25 May 1984.

106 Alheit, NDA, quoted in CAPE Agri-forum Minutes. 
In this regard, it is enlightening to see how the NDA, via its Senior Manager: Land Use and Soil Management ${ }^{107}$ explained how his department interpreted its commitments in terms of the National Environmental Management Principles ${ }^{108}$ and also how the NDA dealt with recommendations or comments by other organs of state. The NDA's approach to its responsibilities in terms of section 2(4)(a) ${ }^{109}$ of the National Environmental Management Act in relation to its consideration of applications for cultivation permits were presented as thus:

The Executive Officer ... is responsible for the administration of (the) ... control measures and when applying his/her mind to such an application considers the norms and standards which apply to the sustainable utilisation of natural resources. Soil conditions (with respect to) the bi-nominal soil classification are considered as well as climatic conditions and suitability of the crops that are envisaged to be planted on the virgin cropland. Furthermore the physical properties such as slope are also taken into consideration. The (executive officer) recognises the fact that other legislation is in place which also regulates the cultivation of natural veldt or so-called virgin soil and therefore when issuing consent to plough virgin soil .... the (executive officer) also brings to the attention of the applicant that the consent issued is subject (to) conditions of other relevant Acts such as ECA, 1973 (sic) (Act No 73 of 1989), NEMA, 1998 (Act No 107 of 1998) and The Water Act, 1998 (Act No 73 of 1998) (sic) Where (the comments or recommendations of other organs of state) impact directly on sustainable agricultural production issues they are taken into consideration and debated until consensus is reached. Occasionally there are points on which we differ ... where our areas of responsibility contradict one another and where consensus is not reached. When such differences arise we restrict ourselves to our terms of reference regarding the administration of CARA to obtain the laid down objectives of the Act. ${ }^{110}$

From this response, it would appear that the NDA recognises that its decisions are subject to conditions that may be imposed by other government mandates, such as those relating to the environment and water resources. What it also reflects, however, is that the national Department of Agriculture appears to stop short of internalising the precepts of the National Environmental Management Act into its own prescribed powers and duties, such as the regulation of

107 Botha "Interpretation" 2005.

108 S 2 of NEMA.

109 "Sustainable development requires the consideration of all relevant factors, including ...".

110 Botha "Interpretation" 2005. 
cultivation. None of the parties to the Agreement has resorted to the mechanisms for dispute resolution which were introduced in 2005 . This is notwithstanding confirmation by both CapeNature and the NDA that discussions around the environmental implications of cultivation have deadlocked occasionally. CapeNature has, furthermore, maintained that such deadlocks have resulted in the loss of threatened biodiversity. If that were so, the ability of the Agreement to deliver on a key aspect of its 'sustainability agenda' — the protection of threatened biodiversity—would need to be queried.

\subsection{The 'pre-NEMA EIA' period: Obstacles that inhibited biodiversity 'mainstreaming' into the issuing of cultivation permits}

The foregoing overview of the 'pre-NEMA EIA' regime has identified a number of facets to the legal and administrative dispensation that appeared individually and cumulatively to have militated against the effective consideration of biodiversity in the course of agri-environmental decision-making in the Western Cape before July 2006. These included regulatory failings, weaknesses in the Agreement and its implementation and narrow interpretation of the NEMA by the NDA. Each of these aspects is presented in summary. The nonimplementation of the 'virgin ground' (Item 10) provision of the amended ECA EIA regulations ${ }^{111}$ in the Western Cape is incontrovertibly the principle reason why environmental prerogatives were not inserted into agricultural decisionmaking between May 2002 and July 2006. The ensuing vulnerability of threatened biodiversity to agricultural transformation was exacerbated further with the restriction of the objectives of integrated environmental management (Chapter 5 of NEMA) to applications for environmental authorisation; responsibility for land-use decisions in critical biodiversity areas became an exclusive agricultural prerogative. ${ }^{112}$ CapeNature's lack of powers to enforce its comments pertaining to biodiversity and the failure of the Agreement to give clear, binding directions as to how the NDA should deal with comments from the DEADP, further compromised the chances of inserting biodiversity 
considerations into the issuing of cultivation permits. In as much as the Agreement provided for environmental (and, by implication, biodiversity) comment on CARA applications, this remained purely formulaic without clear means of ensuring that such comment would be heeded by the NDA and put into practical, enforceable, effect. There is no difference between the aforementioned state of affairs and that which currently prevails in terms of the transformation or removal of less than three hectares of Critically Endangered or Endangered vegetation.

\section{Challenges of integration, consistency and effectiveness: case studies}

Moving to the terrain of actual administration of agri-environmental decisionmaking, a number of examples serve to show how the DEADP and NDA sought to deal with the conundrum described here. These case studies serve to illustrate, on the one hand, inconsistencies which have characterised the DEADP's communication-within the context of the Agreement-of biodiversity considerations to the NDA. They also offer some insight into how the NDA attempted to give effect to its responsibilities under the National Environmental Management Act in relation to the consideration of biodiversity.

\subsection{The Farm 'Welverdiend' 121/2 and 3, Clanwilliam}

On the basis of CapeNature's recommendation, the DEADP instructed (without reference to NEMA section 28, 'the Duty of Care') the CARA applicant to undertake a botanical assessment. A cultivation permit was issued without a botanical assessment. ${ }^{113}$

\subsection{The Farm ' $T$ 'Voetpad' 28/5, Piketberg}

The DEADP did not support the CARA application on the basis of biodiversity considerations. The CARA applicant was advised of its 'general Duty of Care 
obligations' in terms of section 28(1) of the NEMA. However, the CARA applicant was not provided with any guidance or instructions as to what 'reasonable measures' should be adopted to prevent environmental degradation. ${ }^{114}$

\subsection{The Farm 'Steenboksfontein' 133/6, Hopefield}

The DEADP communicated CapeNature's recommendations to the CARA applicant. These included clear instructions such as maintaining a stipulated riparian buffer and $70 \mathrm{~m}$ undeveloped corridors between potato circles. These comments were not, however, formulated with reference to any provisions in law. ${ }^{115}$

\subsection{The Farm 'Verlorenvlei' 8/0, Piketberg}

The DEADP noted that the farm in question fell within the proposed Sandveld biodiversity corridor and that the affected vegetation was classified as Endangered. With reference to the applicant's Duty of Care responsibilities, the DEADP stated it would not oppose the proposed cultivation of virgin soil to establish rooibos tea strips if specified mitigation measures were implemented, including $15 \mathrm{~m}$ buffer strips between fields, placing the higher lying portions of the farm under stewardship (as recommended by CapeNature) and that no development should occur within $50 \mathrm{~m}$ of rocky outcrops. The NDA issued a permit in terms of regulations 2 and 3 of the CARA that reflected these conditions. It specifically noted that such conditions were binding in terms of CARA. ${ }^{116}$

\subsection{Issues arising from case studies}

A number of inferences can be drawn from these examples. Where there was reference to NEMA section 28(1), it had not been supported by any indication as to what the DEADP would have viewed as 'reasonable measures' that

114 DEADP case reference: E12/2/2-AP10-Farm 82/5, Piketberg.

115 DEADP case reference: E12/2/1-92-Farm 113/6, Piketberg.

116 DEADP case reference: E12/2/2-AP10-Verlorenvlei 8/0, Piketberg. 
should have been implemented by the CARA applicant to prevent, minimise or rectify environmental degradation. Alternatively, where the DEADP had informed the CARA applicant through a case officer of practical steps to investigate or reduce the environmental impacts of cultivation, the legal authority informing such recommendations had not been recorded. In contrast, where the department had stipulated mitigatory measures that had be implemented by the CARA applicant, and where this requirement was reinforced by reference to the Duty of Care, such comment could, foreseeably, have been translated into enforceable conditions of approval by the NDA.

\section{Revisiting the NEMA EIA regulations, cultivation of virgin soil and threatened ecosystems}

The NEMA EIA regulations introduced unprecedented opportunity for introducing environmental oversight over the biodiversity aspects of permits for the cultivation of virgin land, but not entirely. One shortcoming is that the regulations stop short of recognising that significant biodiversity considerations still may be applicable when less than three hectares or Vulnerable or Least Threatened indigenous vegetation is to be removed for the purposes of cultivation. Impacts at this scale could be irreversible for plant species and communities associated with special habitats such as quartz patches, silcrete outcrops or seasonal wetlands. Highly localised transformation of less than three hectares in extent also could compromise the viability of vegetation that provides functional connectivity in highly fragmented ecosystems. ${ }^{117}$ Of greatest concern, though, is the failure of the regulations to extend protection to Critically Endangered and Endangered vegetation in patches of less than three hectares in extent. These highly threatened remnants of a globally unique biodiversity will be exposed to transformation without any environmental protection pending the listing of threatened ecosystems under section 52 of NEMBA, which is unlikely to be soon. Experience of the agri-environment regulatory regime in the Western Cape therefore strongly suggests that the 
'new' dispensation under NEMA has inherited one of the key failings of the preJuly 2006, 'ECA order'-the lack of a self-evident legal and uncontested mechanism to ensure that comments on the environmental implications of cultivation have binding effect on permits issued under CARA where cultivation would entail the destruction of threatened vegetation where it occurs in patches of less than three hectares in extent.

The Botanical Society of South Africa views it as critical to identify and implement measures that will forestall the uncontrolled and unmitigated loss of highly fragmented habitat associated with ecosystems already identified as Critically Endangered and Endangered by the National Spatial Biodiversity Assessment. ${ }^{118}$ Such a step is not only necessary to ensure compliance with the National Environmental Management Principles and South Africa's international biodiversity commitments, but would reduce the likelihood of appeals against agricultural decisions that may result in the loss of biodiversity in threatened ecosystems. It must be borne in mind that CapeNature-owing to the mandate it obtains from the Western Cape Nature Conservation Board Act 15 of $1998^{119}$ _and its key role in the implementation of the CAPE programme, in many instances would be compelled to take a firm stand against such loss of threatened biodiversity.

\section{Options for integrating biodiversity considerations into cultivation permits}

Bearing the research question to this article in mind, this section summarises a number of proposed options for integrating environmental and biodiversity considerations, in the form of enforceable mechanisms, into decisions and permits pertaining to the cultivation of virgin soil which do not 'trigger' the requirement for an environmental authorisation.

118 Driver et al supra $\mathrm{n} 2$.

119 Including "...the conservation of naturally-occurring ecological systems and the sustainable utilisation of indigenous plants and animals and the promotion and maintenance of biological diversity within those systems...". 


\subsection{Option 1 - Consolidated DEADP and CapeNature comment is appended to the CARA permit}

In terms of this option, the addition of 'environmental' conditions to a cultivation permit issued in terms of the Conservation of Agricultural Resources Act would reflect the NDA's compliance with NEMA section 2, thereby confirming that the NDA has referred to the National Environmental Management Principles as guidelines by which it must exercise any function when taking decisions in terms of NEMA or any statutory provision concerning the protection of the environment). The Applicant's Duty of Care obligations under NEMA section 28(1), and related provisions for their enforcement, including recovery of remediation costs by the State, also would be made explicit. ${ }^{120}$

\subsection{Option 2 - Consolidated DEADP and CapeNature comment is integrated as conditions of approval into the CARA permit ${ }^{121}$}

In terms of this option, the NDA would treat 'environmental' comments and recommendations as 'prohibitions' or 'obligations' ${ }^{122}$ ancillary to those provided for in Control Measures prescribed in terms of section 6 of the Conservation of Agricultural Resources Act. In other words, these conditions would not discriminate between the respective agricultural and environmental mandates pertaining to agri-environmental decision-making. Instead, these considerations would be synthesised into a single set of 'prohibitions' or 'obligations' prescribed by the responsible executive officer as mandated to exercise powers and duties conferred by the Conservation of Agricultural Resources Act. ${ }^{123}$ 


\subsection{Option 3 - Consolidated DEADP and CapeNature comment is issued as a directive under section 28(4) of NEMA}

Here, consolidated DEADP and CapeNature comment is formulated as a directive in terms of NEMA section 28(4) that instructs the CARA applicant to take specific reasonable measures to modify and control any activity that may cause environmental degradation. ${ }^{124}$

\subsection{Option 4 - A directive is issued in terms of NEMA section 28(3), calling for investigation into potential environmental impacts}

Alternatively, if DEADP or CapeNature were to require more information before they can reach an informed decision about the potential environmental impacts of a CARA permit, a directive can be used to instruct the CARA applicant to undertake any of the measures prescribed in NEMA section 28(3) (for example, to investigate, assess and evaluate the impacts on the environment) to inform such decision.

\subsection{Authorisation}

In situations where DEADP and/or CapeNature believe that environmental (and biodiversity) considerations have not been addressed adequately in the CARA application process, or in a CARA permit, these organs of state can resort to the procedures for conflict avoidance and resolution in the Agreement (compare Section 4) so as to settle and resolve differences of opinion that may have arisen around the environmental aspects of a cultivation decision. 


\subsection{Option 6 - Section 31A order to cease activity ${ }^{125}$}

Section 31A of the Environment Conservation Act 73 of 1989 can be invoked by the DEADP to eliminate, reduce or prevent the environment being seriously damaged, endangered or detrimentally affected as result of a cultivation permit.

\subsection{Evaluation}

Option 2 would appear to be most desirable from the perspective of ensuring that environmental considerations are factored into the NDA's own authorisation procedures. However, option 1 may be more acceptable to the NDA which has expressed reservations about the extent to which NEMA defines and circumscribes its statutory mandate as defined by the objectives of CARA. Under this option, the NDA's Directorate: Land Use and Soil Management would be relieved of having to take direct responsibility for an 'environmental' mandate, instead relying on the DEADP to do so on its behalf. This would, however, require agreement from the NDA to append such environmental comments, as enforceable conditions of approval, to the CARA permit. Options 1 and 2 would require amendment to the NDA's standard permission to cultivate virgin soil in order to integrate it more closely with NEMA.

Options 3 and 4 differ from option 1 in that they squarely place responsibility and the power for defining and enforcing compliance with the environmental aspects of cultivation permits with the DEADP and within the direct purview of NEMA. The NDA would clearly have to be consulted, though, in terms of section 28(4) of NEMA before a directive can be issued. The advantage of this approach is that option 3 recognises that cultivation of virgin land is an activity that can be authorised by law, and that it can entail environmental degradation that cannot reasonably be avoided or stopped. Such degradation must, however, be minimised and remedied (that is, through measures translated into conditions of approval) in terms of the CARA permit holder's Duty of Care. Option 4 , in turn, introduces the possibility for undertaking an appropriate level 
of environmental investigation in support of informed decision-making in the sphere of agricultural resource conservation. Disputes arising from the implementation of options 3 or 4 would have to be resolved in terms of the Agreement or, failing this, the provisions for fair decision-making and conflict management as provided for in Chapter 4 of NEMA.

Option 5 is viewed as less desirable than those outlined above. It assumes that there are no alternatives to the status quo regarding the implementation of the Agreement. It tacitly acknowledges the perception that DEADP and CapeNature do not have binding powers or influence over the inclusion of environmental and biodiversity factors in the regulation of applications for the cultivation of virgin land where less than three hectares of threatened vegetation may be at stake. This is clearly anathema to the principles and objectives of co-operative governance.

Option 6 represents the extreme case: it can be used pre-emptively by the DEADP to prevent environmental harm arising from the implementation of a cultivation permit, or reactively where environmental harm already may have resulted from the issuing of a cultivation permit. It is viewed as an option of last resort.

The aims of the Agreement are couched within the framework for co-operative governance and integrated decision-making. They set out to ensure that the regulatory objectives of all the authorities are being satisfactorily served; decision-making is well informed and integrated; administrative action is lawful, reasonable and procedurally fair; and that actual and potential conflicts are resolved.

The options presented here for integrating environmental and biodiversity considerations into cultivation permit are assessed against the degree to which they satisfy the above criteria, besides that on conflict resolution. 'Conflictresolution' is understood to refer to disputes that may relate to the interpretation and implementation of the Agreement and therefore is not included as an assessment criterion. 


\begin{tabular}{|c|c|c|c|c|c|c|c|}
\hline OPTION & $\begin{array}{l}\text { Does it } \\
\text { further the } \\
\text { objectives of } \\
\text { co-operative } \\
\text { governance? }\end{array}$ & $\begin{array}{l}\text { Does it } \\
\text { support } \\
\text { integrated } \\
\text { decision- } \\
\text { making? }\end{array}$ & $\begin{array}{l}\text { Does it } \\
\text { serve the } \\
\text { regulatory } \\
\text { objectives } \\
\text { of the } \\
\text { NDA? }\end{array}$ & $\begin{array}{l}\text { Does it } \\
\text { serve the } \\
\text { regulatory } \\
\text { objectives } \\
\text { of the } \\
\text { DEADP? }\end{array}$ & $\begin{array}{l}\text { Does it } \\
\text { ensure that } \\
\text { decision- } \\
\text { making is } \\
\text { well } \\
\text { informed \& } \\
\text { integrated? }\end{array}$ & $\begin{array}{l}\text { Does it } \\
\text { support } \\
\text { administrative } \\
\text { action that is } \\
\text { lawful, } \\
\text { reasonable \& } \\
\text { procedurally } \\
\text { fair? }\end{array}$ & $\begin{array}{c}\text { TOTAL } \\
\text { Max= } \\
18\end{array}$ \\
\hline 1 & Yes & Partly & Yes & Yes & Partly & Yes & 16 \\
\hline 2 & Yes & Yes & Yes & Yes & Yes & Yes & 18 \\
\hline 3 & Partly & Partly & Yes & Yes & Partly & Yes & 15 \\
\hline 4 & Partly & Partly & Yes & Yes & Partly & Yes & 15 \\
\hline 5 & No & No & Partly & Partly & No & No & 8 \\
\hline 6 & No & No & No & Yes & No & No & 8 \\
\hline
\end{tabular}

Yes $=3$, Partly $=2$, No $=1$

In terms of this scoring, integrating environmental conditions of authorisation into CARA permits as section 6 'prohibitions' or 'obligations' or, alternatively, appending them as provisions enforceable by NEMA section 28, would appear to satisfy most effectively the aims of the Agreement. Option 5 (the status quo) and option 6 emerge as being least consistent with the aims of the Agreement. The two options that rely on the use of directives (3 and 4) also largely satisfy the aforestated aims. Their implementation would, however, require a change in attitude towards directives which seem to hold a punitive connotation, rather than a reputation for facilitating informed decision-making and encouraging a risk-averse and cautious approach to project planning and implementation.

\section{Conclusion}

Placing globally threatened biodiversity on an equal footing to the conservation of the agricultural potential of land, where the latter is clearly prescribed by law but the former not, poses both legal and administrative challenges. It is difficult to see, however, how the responsible authorities can stand shy of this in the face of firm constitutional guarantees against ecological degradation. The rights to inter-generational equity and the ecologically sustainable use of natural resources are similarly unambivalent. Likewise, the authorities in question exercise their duties within a legislative framework that makes very clear demands with regard to the loss of biodiversity and ecosystem functioning: it 
must be avoided and, only when that is not possible, mitigated and remedied. Prevention and precaution represent two bedrock principles in our environmental legislation. Indeed, the authorities themselves have made commitments, at the level of agreed measures to co-ordinate different statutory mandates and decisions relating to cultivation, to the shared goal of sustainable agricultural development. Translating these commitments into credible actions that attest to the undertakings and objectives by which they were motivated has, unfortunately, proven to be challenging in practice.

In this context, section 28 of NEMA appears to be a worthy contender for factoring biodiversity considerations into permits for the cultivation of virgin soil where the extent of loss of threatened vegetation falls short of the quantitative threshold for statutory protection by means of the EIA system. It has been argued that the most desirable option for achieving the aims of the Agreement in question would be the voluntary inclusion, by the NDA, of environmental and biodiversity-related comments as conditions of authorisation in ploughing permits. By the same token, though, it is recognised that such an approach depends on the willingness of the NDA to claim and internalise responsibility for 'environmental' powers that, administratively, vest with another department. The alternative, which is possibly more pragmatic and mindful of sensitivities that may arise around the definition of intra-governmental powers and functions, would be to use directives under section 28 of NEMA to extend 'environmental' considerations into decisions that traditionally have been the exclusive purview of the national agricultural function in government. It is assumed that a NEMA section 28(4) directive can be used pre-emptively, in support of informed decision-making, and not only as an emergency measure or 'administrative truncheon'. This may be more of a question of perception than one of law.

Generally, though, it is concluded that either of the broad options outlined here would result in the effective incorporation of binding environmental (and biodiversity) conditions into permits issued under sections 6 and 29 of CARA. In particular, it is argued that the options outlined here present feasible and effective means of extending urgently needed protection to highly fragmented 
habitat in Critically Endangered and Endangered ecosystems while they have no security from a listing in terms of section 52 of NEMBA.

In many instances, these remnant patches of globally threatened biodiversity are far less than three hectares in extent-which currently will permit them to be whittled away to the point of extinction, unprotected by the weave of the NEMA EIA regulations. 


\section{Bibliography}

Botha "Interpretation" 2005

Botha MJ "Interpretation" in Correspondence between the Manager: Land and Monitoring, National Department of Agriculture and the Botanical Society of South Africa (15 March 2005)

Bowie "Land-use Advice"

Bowie V "Land-use Advice in Cape Nature" in CapeNature Biodiversity Review (Driftsands Nature Reserve Kuils River 26 October 2005)

\section{CAPE Agri-forum Minutes}

Cape Action for People and the Environment Agricultural Forum Minutes of 24 August 2005 (Rufford Maurice Laing Centre for Biodiversity Conservation Kirstenbosch)

Cowling "Foreword" 7

Cowling RM "Foreword" in De Villiers CC (ed) Fynbos Forum Ecosystem Guidelines for Environmental Assessment in the Western Cape (Fynbos Forum \& BSSA Kirstenbosch 2005)

Cowling et al Framework for a Conservation Plan 16

Cowling RM et al Framework for a Conservation Plan for the Cape Floristic Region, South Africa IPC Report 9902 prepared for WWF-SA Stellenbosch (UCT Rondebosch 1999)

Cox and Youens Review

Cox D and Youens K Review of the agricultural application procedure: Alignment of the CARA and ECA Application Processes (Department of Agricultural and Environmental Affairs KwaZulu-Natal 2005)

\section{CSIR Situation Assessment}

CSIR Consortium Situation Assessment for the Policy, Legal, Institutional, 
Financial, Social and Economic Component (Module 3) of the CAPE Project (CSIRMWF-SA Stellenbosch 1999)

De Villiers and Turner "Managing Agricultural Land Transformation"

De Villiers CC and Turner I "Managing Agriculture Land Transformation in the Cape Floristic Region: An Overview" in IAIAsa 2000 National Conference Proceedings (IAIAsa Goudini Spa 30 September-4 October 2001)

De Villiers et al "Developing Guidelines"

De Villiers CC et al "Developing Guidelines for Incorporation of Biodiversity Considerations in Environmental Assessment: The Experience of the Fynbos Forum" in IAIAsa 2004 National Conference Proceedings (IAIAsa Champagne Sports Resort Drakensberg KwaZulu-Natal 17-20 October 2004)

De Villiers et al Fynbos Forum Ecosystem Guidelines

De Villiers CC et al Fynbos Forum Ecosystem Guidelines for Environmental Assessment in the Western Cape (Fynbos Forum \& BSSA Kirstenbosch 2005)

\section{DEA Guideline Document}

Department of Environmental Affairs Integrated Environmental Management Guideline Series: Documents 1-6 (DEA Pretoria 1992)

\section{DEADP Presentation}

Department of Environmental Affairs and Development Planning Presentation to the Steering Committee for the Supplementation of the EIA regulations to be promulgated in terms of s 24(2) of the National Environmental Management Act, Act 107 of 1998 (as amended) (DEADP Cape Town 2 February 2006) 
Driver et al 2005 Strelitzia

Driver A et al "National Spatial Biodiversity Assessment 2004: Priorities for Biodiversity Conservation in South Africa" 2005 Strelitzia 17

Glasson et al Introduction 4-6

Glasson J, Therivel R and Chadwick A Introduction to Environmental Impact Assessment (UCL Press London 2005)

Mittermeier et al Hotspots

Mittermeier RA et al Hotspots Revisited: Earth's Biologically Richest and most Endangered Terrestrial Ecoregions (CEMEX Agrupación Serra Madre SC Mexico 2005)

Mucina and Rutherford 2006 Strelitizia 19

Mucina L and Rutherford MC (eds) "The Vegetation of South Africa, Lesotho and Swaziland" 2006 Strelitzia 19

Preston et al IEM 748-761

Preston G, Robins N and Fuggle RF "Integrated Environmental Management" in Fuggle RF and Rabie MA (eds) Environmental Management in South Africa (Juta Kenwyn 1996)

Rouget et al NSBA Technical Report

Rouget M et al South African National Spatial Biodiversity Assessment 2004 Technical Report Volume 1 Terrestrial Component (SANBI Pretoria 2004)

SANBI NBSAP

South African National Biodiversity Institute South Africa's National Biodiversity Strategy and Action Plan Final Draft 6 May 2005 (SANBI Pretoria 2005)

Sandwith et al Mainstreaming Biodiversity

Sandwith T et al "Mainstreaming Biodiversity through South Africa's $40 / 42$ 
Bioregional Conservation Programs: Top-Down, Bottom-Up" in Petersen C and Huntley B (eds) Mainstreaming Biodiversity in Production Landscapes (Global Environment Facility Washington DC 2005)

Scholes and Biggs (eds) "Ecosystem services in South Africa" 18

Scholes RJ and Biggs R (eds) "Ecosystem Services in Southern Africa: A

Regional Assessment: A contribution to the Millennium Ecosystem

Assessment, prepared by the regional-scale team of the Southern African

Millennium Ecosystem Assessment" (CSIR Pretoria 2004)

Von Hase et al Cape Lowlands Renosterveld

Von Hase A et al A Fine-Scale Conservation Plan for Cape Lowlands

Renosterveld Report No CCU 2/03 (BSSA Kirstenbosch 2003)

\section{Register of legislation}

Conservation of Agricultural Resources Act 43 of 1983

Constitution of the Republic of South Africa 1996

Environment Conservation Act 73 of 1989

GN R385 Government Gazette 28753 of 21 April 2006

GN R386 Government Gazette 28753 of 21 April 2006

GN R387 Government Gazette 28753 of 21 April 2006

GN R670 Government Gazette 2340110 May 2002

GN R672 Government Gazette 2340110 May 2002

GN R1182 Government Gazette 182615 September 1997

GN R1183 Government Gazette 182615 September 1997

GN R1184 Government Gazette 182615 September 1997

GN R1048 Government Gazette 923825 May 1984

National Environmental Management Act 107 of 1998

National Environmental Management Second Amendment Act 8 of 2004

National Environmental Management: Biodiversity Act 10 of 2004

National Water Act 36 of 1998

Promotion of Administrative Justice Act 3 of 2000

Western Cape Nature Conservation Board Act 15 of 1985 


\section{List of abbreviations}

BSSA Botanical Society of South Africa

CAPE Cape Action for People and the Environment

CARA Conservation of Agricultural Resources Act

cf compare

ch chapter(s)

CSIR Council for Scientific and Industrial Research

DEA Department of Environment Affairs

DEADP Department of Environmental Affairs and Development Planning

DEAT Department of Environmental Affairs and Tourism

DECAS Department of Environmental and Cultural Affairs and Sport

DWAF Department of Water Affairs and Forestry

ECA Environment Conservation Act

eg for example

EIP Environmental Implementation Plan

ie that is

MoU Memorandum of Understanding

NBSAP National Biodiversity Strategy and Action Plan

NDA National Department of Agriculture

NEMA National Environmental Management Act

NEMBA National Environmental Management Biodiversity Act

NSBA National Spatial Biodiversity Assessment

par paragraph(s)

PDA Provincial Department of Agriculture

S section(s)

SANBI South African National Biodiversity Institute

sch schedule(s)

subs subsection(s)

UCT University of Cape Town

WCNCBA Western Cape Nature Conservation Board Act 